\title{
Persepsi Pemimpin Dan Pemilik Klinik Terhadap Akreditasi Klinik
}

\author{
Arlina Dewi ${ }^{1}$ \\ 1. Magister Administrasi Rumah Sakit, Universitas Muhammadiyah Yogykarta, Bantul, Indonesia \\ Gedung Pascasarjana Lantai 2, Jalan Lingkar Selatan, Tamantirto, Kasihan, Bantul, Yogyakarta, Indonesia, 55183, Telepon +62 \\ 274387656 \\ Email: arlinadewi@umy.ac.id \\ DOI: 10.18196/ppm.39.129
}

\begin{abstract}
Abstrak
Tujuan akreditasi fasilitas kesehatan adalah penyediaan pelayanan yang bermutu dan aman bagi masyarakat. Di Indonesia, klinik yang terakreditasi baru mencapai 10\% dari 7.917 klinik. Aisyiyah-Muhammadiyah merupakan ormas Islam yang fokus pada bidang kesehatan dengan 231 klinik. Namun, hanya enam klinik yang memenuhi standar akreditasi. Pengabdian kepada masyarakat ini bertujuan mengetahui persepsi pimpinan klinik dan karyawan tentang komitmen mempersiapkan akreditasi setelah mengikuti pelatihan akreditasi klinik. Pengabdian kepada masyarakat ini menggunakan metode deskriptif kuantitatif dengan kuesioner terbuka. Kuesioner terbuka dibagikan kepada responden setelah mengikuti pelatihan akreditasi klinis selama 3 hari yang diselenggarakan oleh Aisyiyah Pimpinan Pusat. Responden dalam pengabdian masyarakat ini adalah Pimpinan Daerah Aisyiyah, Pimpinan, dan Tim Kualitas Puskesmas Aisyiyah, dengan 25 responden dari 11 Puskesmas Rawat Inap dan 7 Puskesmas Rawat Jalan yang tersebar di sepuluh provinsi di Indonesia. Analisis data dalam pengabdian masyarakat ini menggunakan software (Nvivo 12plus). Hasil pengabdian masyarakat ini menyoroti tiga faktor penting yang dapat menghambat penyusunan akreditasi, yaitu faktor internal staf yang meliputi pengetahuan, kesadaran, dan kesiapan untuk melakukan akreditasi; faktor klinis meliputi sarana dan prasarana, pelayanan operasional, sumber daya manusia dan dana; dan faktor komitmen pemilik dan staf klinik. Proses akreditasi tidak hanya untuk memenuhi kewajiban, tetapi juga untuk mencapai budaya pelayanan kesehatan yang bermutu dan memberikan manfaat bagi kesehatan pasien.
\end{abstract}

Kata Kunci: akreditasi, kualitas layanan, komitmen

\section{Pendahuluan}

Konteks kualitas perawatan kesehatan tidak ambigu dan lugas, tetapi bernuansa dan fleksibel. Dalam lingkungan perawatan kesehatan saat ini, tantangannya adalah memberikan perawatan pasien yang berkualitas dan aman (Nicklin et al., 2017). Memastikan kualitas adalah kunci sistem kesehatan berkinerja tinggi. Akses ke perawatan kesehatan saja tidak cukup: pasien yang bergabung dengan sistem perawatan kesehatan baik klinik, rumah sakit, atau lokasi lain perlu diyakinkan bahwa mereka akan menerima perawatan yang aman, efektif dan berkualitas dengan bukti klinis terbaru (Jha, 2018). Sektor perawatan kesehatan menjadi perhatian kebijakan utama di seluruh dunia karena biayanya yang mahal, pengaruhnya terhadap kesejahteraan penduduk.

Kualitas pelayanan kesehatan yang rendah berpengaruh signifikan terhadap masyarakat dan sistem kesehatan yang tecermin dalam banyak aspek, misalnya pelayanan yang tidak efisien sehingga tidak membuahkan hasil yang diharapkan; layanan tidak efektif dengan biaya tinggi untuk mencapai hasil yang sama; layanan yang tidak memadai secara geografis, politik, budaya dan sosial menunjukkan waktu tunggu yang lama dan ketidakpuasan konsumen dan profesional kesehatan (Organización Panamericana de la Salud et al., 2007). Kualitas perawatan rendah, dan perawatan kesehatan yang tersedia lebih buruk (Sharma et al., 2017).

Reformasi penting dalam organisasi kesehatan dan kesehatan masyarakat salah satunya adalah akreditasi (Agence Nationale d'Accréditation and d'Évaluation en Santé, 1999). Akreditasi merupakan salah satu metode untuk mengevaluasi dan memelihara mutu pelayanan kesehatan (WHO, 2003). Proses dan pelaksanaan akreditasi akan menjadi kekuatan dan pada akhirnya meningkatkan kualitas pelayanan secara terukur (Nicklin et al., 2017). Aspek kritis unik dari akreditasi layanan perawatan kesehatan adalah dimasukkannya standar dan metodologi 
evaluasi. Pendekatan akreditasi memeriksa "sistem" utama rumah sakit dan bagaimana mereka bekerja sama untuk menyediakan layanan yang aman dan berkualitas (Francis, 2013).

Tujuan terakreditasi fasilitas kesehatan adalah penyediaan pelayanan yang bermutu dan aman bagi masyarakat. Standar akreditasi memengaruhi fasilitas kesehatan, kualitas klinis, dan staf (Greenfield et al., 2012). Selain itu, akreditasi fasilitas kesehatan berdampak pada praktik yang efisien dan berkualitas yang mengakibatkan penurunan lama rawat inap, penurunan angka kematian di layanan kesehatan, dan penurunan biaya (Piontek et al., 2003). Prinsip-prinsip ini telah dikembangkan sebagai deklarasi harapan yang diperlukan untuk menetapkan kriteria kesehatan pasien, jaminan kualitas yang konsisten, dan perawatan yang berfokus pada pengguna layanan/konsumen (ISQua, 2015).

Di Indonesia, klinik yang terakreditasi baru mencapai 10\% dari 7.917 klinik setelah Kementerian Kesehatan mengeluarkan Peraturan Nomor 46 Tahun 2015 (Kementerian Kesehatan RI, 2015; Kementrian Kesehatan RI, 2019). Aisyiyah-Muhammadiyah adalah organisasi Islam yang bergerak dalam bidang kesehatan. Pada tahun 2019, AisyiyahMuhammadiyah dalam kegiatan pelatihan persiapan akreditasi klinik memiliki 231 klinik, tetapi hanya enam klinik yang memiliki standar akreditasi. Tujuan dari pengabdian masyarakat ini untuk mengetahui persepsi pimpinan klinik dan karyawan tentang komitmen mempersiapkan akreditasi setelah mengikuti pelatihan akreditasi klinik.

\section{Metode Pelaksanaan}

Pengabdian kepada masyarakat ini menggunakan metode deskriptif kuantitatif dengan desain cross-sectional. Responden dalam pengabdian masyarakat ini adalah Pimpinan Daerah Aisyiyah, Pimpinan Puskesmas, dan Tim Mutu Klinik yang pernah mengikuti pelatihan di Yogyakarta. Teknik pengambilan sampel menggunakan random sampling sebanyak 25 responden dari 48 responden yang mendapat pelatihan dan mewakili 18 klinik dari 11 rawat inap dan tujuh klinik rawat jalan Aisyiyah di 10 provinsi di Indonesia. Pengabdian kepada masyarakat ini menggunakan dua tahap, yaitu tahap pertama, semua sampel mendapatkan pelatihan persiapan akreditasi klinis selama tiga hari dan tahap kedua, responden yang mengikuti pengabdian masyarakat ini mengisi kuesioner terbuka untuk persiapan akreditasi klinis. Analisis data dalam pengabdian masyarakat ini menggunakan software (Nvivo 12plus) untuk menganalisis data dalam bentuk transkrip.

\section{Hasil dan Pembahasan}

Klinik yang digunakan dalam pengabdian masyarakat ini merupakan amal usaha Aisyiyah fasilitas kesehatan tingkat pertama yang berasal dari 10 provinsi dari 34 provinsi di Indonesia yang sebagian besar belum terakreditasi.

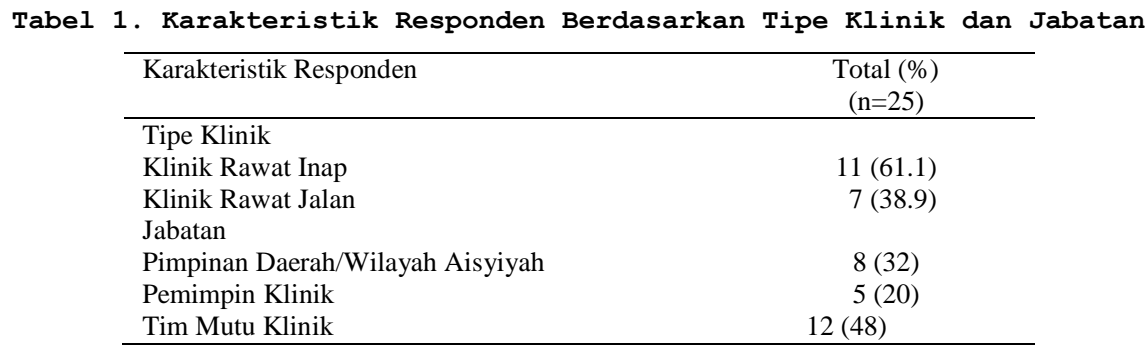

Berdasarkan Tabel 1., sebagian besar Klinik Aisyiyah yang mengikuti pengabdian masyarakat ini berasal dari 11 klinik rawat inap $(61,1 \%)$ dan 7 klinik rawat jalan $(38,9 \%)$, sebagian besar responden adalah tim mutu klinik sebanyak 12 orang (48\%), Pimpinan daerah Aisyiyah sebanyak 8 orang (32\%), dan pimpinan klinik sebanyak 5 orang (20\%). 


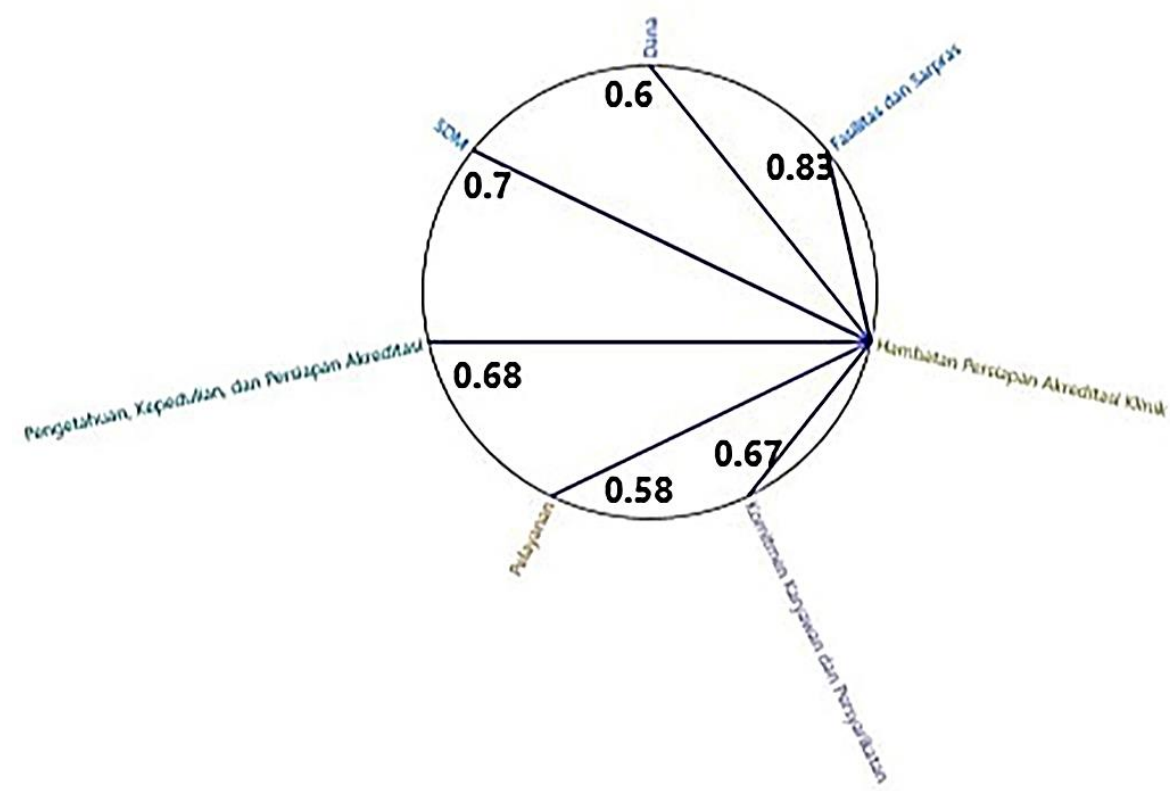

Gambar 1. Kendala Klinik Rawat Inap dan Rawat Jalan Aisyiyah dalam Mempersiapkan Akreditasi Klinik

Berdasarkan Gambar 1., kendala yang dialami Klinik Aisyiyah dalam mempersiapkan akreditasi sangat berkaitan dengan faktor internal individu, yaitu pengetahuan, kesadaran, dan kesiapan menjalani akreditasi; faktor klinis meliputi sarana dan prasarana, pelayanan operasional, sumber daya manusia dan dana; dan komitmen karyawan atau staf dan pemilik klinik (organisasi) dalam melakukan akreditasi klinik. Hal ini ditunjukkan dengan nilai koefisien antara $\pm 0,5$ dan \pm 1 .

Kondisi ideal, persiapan akreditasi akan berada di bawah kepemimpinan bersama dari dokter, perawat, manajer, dan karyawan lainnya (Pomey et al., 2005). Hambatan akreditasi termasuk hambatan struktural (praktik umum), hambatan sumber daya (kekurangan staf atau uang) dan hambatan budaya (kecurigaan oleh praktisi atau kesulitan mengatasi budaya tanggung jawab yang dirasakan berkorelasi dengan penilaian kualitas) (Campbell et al., 2002). Penerapan dan konsekuensi akreditasi klinis tidak banyak diketahui dalam praktik umum. Pimpinan dan pemilik klinik baik rawat inap maupun rawat jalan menyadari bahwa mereka mempunyai kendala dalam mempersiapkan akreditasi, yaitu faktor internal dari petugas, faktor klinis, dan komitmen pegawai atau petugas klinik dan pemilik untuk meningkatkan mutu klinik melalui akreditasi.

Kendala dalam mempersipkan akreditasi dari faktor internal staf dikarenakan rendahnya pengetahuan, kepedulian terhadap karyawan atau staf, dan belum siap melaksanakan akreditasi. Tabandeh et al. (2016) menjelaskan bahwa kegagalan fasilitas kesehatan pada tingkat akreditasi disebabkan oleh pengetahuan umum dan sikap karyawan dalam mempersiapkan akreditasi. Kurangnya pengetahuan ini bermasalah dalam hal pengambilan keputusan berdasarkan bukti yang lebih banyak mengenai pengembangan, pengenalan, dan implementasi sistem akreditasi (Hinchcliff et al., 2012; Saadati et al., 2015). Memahami persyaratan akreditasi merupakan tantangan utama bagi para profesional selama persiapan akreditasi (Due et al., 2019). Kurangnya pengetahuan akan berdampak pada ketidaksiapan karyawan sebagai pelaksana asuhan yang dievaluasi.

Akreditasi menjadi tantangan karena merupakan konsep dan proses baru serta banyak karyawan takut gagal dan skeptis terhadap manfaat praktis dari akreditasi yang sebagian besar berfokus pada kebijakan dan prosedur (Alyahya et al., 2018), berdampak pada standar perawatan klinis dan biaya akreditasi perawatan kesehatan (Alkhenizan and Shaw, 2012). Sistem akreditasi yang diwajibkan dianggap sebagai mekanisme pemantauan pemerintah terhadap fasilitas 
kesehatan yang dapat menyebabkan ketidakpercayaan pada profesional kesehatan (Pomey et al., 2005) karena proses peningkatan kualitas hanya sebagai formalitas akreditasi (Pongpirul et al., 2006), dan sikap pimpinan pelayanan kesehatan yang negatif dan manfaat akreditasi yang tidak mapan (Alkhenizan and Shaw, 2012). Skeptisisme dan penolakan dianggap menghalangi kemajuan karena penolakan pribadi untuk berubah (Gollop et al., 2004). Masalah ini membuat staf tidak siap untuk akreditasi karena keraguan diri dan pandangan negatif tentang akreditasi sebelum mencoba melakukannya.

Konteks untuk memastikan bahwa individu dan organisasi memahami nilai, manfaat, dan pentingnya proses akreditasi (Desveaux et al., 2017) melalui sikap dan pengetahuan staf dengan memberikan pelatihan yang memadai (Tabrizi et al., 2019) tentang akreditasi, cara pelaksanaan, dan manfaatnya perlu ditingkatkan. Hal ini berguna untuk mengembangkan budaya yang tepat bagi manajer dan karyawan untuk memastikan skema akreditasi (Tabandeh et al., 2016). Prosedur dan praktik akreditasi telah dilaksanakan di pelayanan kesehatan, meskipun seringkali secara informal (Melo, S, 2016). Program pelatihan menciptakan pengertian tentang apa yang mereka sebut sebagai budaya akreditasi seperti kebijakan, prosedur, standar, dan kualitas akreditasi (Alyahya et al., 2018; Saadati et al., 2015).

Para pemimpin dalam mengupayakan perbaikan persepsi staf tentu perlu mengidentifikasi dampak dari sikap skeptis dan oposisi serta memahami bagaimana orang dapat terlibat dalam perubahan secara positif (Gollop et al., 2004), seperti melakukan kegiatan benchmarking untuk mencapai akreditasi dengan mempelajari tentang proses akreditasi dan harapan untuk mengadopsi beberapa praktik dan aktivitas untuk mencapai akreditasi (Alyahya et al., 2018; Mumford et al., 2015). Akreditasi layanan kesehatan tidak dapat diabaikan dan diragukan. Hal ini menjadi bagian dari tugas penyedia layanan kesehatan untuk mencapai kualitas dan akreditasi sebagai cara untuk meningkatkan budaya sistem perawatan kesehatan sebagai target akhir. Kinerja atau kegagalan bergantung pada keyakinan bahwa ini adalah peluang sukses untuk meningkatkan keamanan, kemanjuran, dan efisiensi perawatan demi kepentingan pasien yang kita layani.

Kendala dalam penyusunan akreditasi selanjutnya karena faktor klinis, seperti belum tersedianya sarana dan prasarana yang memadai, pelayanan operasional secara manual, minimnya dana, dan pengaruh pemilik klinik. Kendala akreditasi kesehatan antara lain kurangnya sumber daya dan prasarana, sumber daya sarana, sumber keuangan yang tidak memadai, sumber daya manusia, dan kurangnya dukungan untuk manajemen senior (Mosadeghrad et al., 2019; Tabrizi et al., 2019; Zarifraftar and Aryankhesal, 2016). Manajemen sumber daya manusia, perawatan klinis, sistem informasi, manajemen obat dan manajemen perilaku, merupakan kunci kegagalan dalam proses akreditasi (Yu et al., 2020). Kendala faktor klinis menyebabkan pelayanan kesehatan pasien belum optimal, efektif, dan aman. Hal tersebut membuat klinik tersebut belum siap memenuhi standar akreditasi khususnya dalam pelayanan kesehatan.

Keberhasilan implementasi program akreditasi membutuhkan sumber daya yang memadai (Tabrizi et al., 2019). The World Health Organization (WHO) mendorong investasi dalam sistem informasi kesehatan dalam layanan, mengutip bukti untuk meningkatkan manajemen pasien, efisiensi klinis dan hasil kesehatan (WHO, 2006), untuk mendukung perawatan kesehatan terintegrasi yang berkelanjutan dan berkualitas (Yu et al., 2009). Jiang dan Yu menjelaskan bahwa penerapan dan pemanfaatan sistem informasi kesehatan dapat menjadi metode yang efektif untuk memenuhi persyaratan akreditasi (Jiang and Yu, 2015). Sistem akreditasi standar dianggap sebagai pilar utama untuk melindungi hak-hak pasien dan orang lain serta untuk memelihara sistem perawatan kesehatan yang terintegrasi. Akreditasi berupaya menyelesaikan kualitas perawatan kesehatan sektor swasta, dengan upaya untuk meningkatkan akses, lembaga kesehatan publik/nonpemerintah, dan publik (Embrey et al., 2016). Kebutuhan akan pelayanan kesehatan yang lebih baik, tidak hanya di rumah sakit, tetapi juga di pelayanan kesehatan primer (WHO, 2006). Namun, pada kenyataannya pemanfaatan pelayanan kesehatan berbasis sistem 
informasi masih minim. Ini adalah langkah besar dan hanya berhasil dicapai di beberapa institusi perawatan kesehatan hingga saat ini.

Hambatan bagi staf dan pemilik klinik untuk berkomitmen meningkatkan mutu klinik melalui akreditasi. Hambatan akreditasi, termasuk kurangnya komitmen dari manajer dan dokter, digambarkan sebagai kendala utama dalam akreditasi yang sangat baik (Saadati et al., 2015). Kurangnya keterlibatan dokter dilaporkan menjadi penghalang untuk perbaikan (Mary et al., 2007) karena keterlibatan staf yang tidak memadai telah diidentifikasi sebagai hambatan utama dalam proses akreditasi (El-Jardali et al., 2008; Pongpirul et al., 2006). Selama persiapan, manajer perawatan kesehatan harus menekankan bahwa akreditasi bukanlah prioritas utama, tetapi lebih menekankan pada bagaimana sistem akan mengubah budaya dan meningkatkan kualitas, keamanan, efisiensi, dan keandalan layanan (Chiu et al., 2011). Fokus utama pegawai, pimpinan, dan pemilik layanan kesehatan adalah berkomitmen dan mendukung untuk meningkatkan mutu pelayanan kesehatan budaya agar tidak sebatas memenuhi persyaratan standar akreditasi.

Keterlibatan staf sebagai upaya komitmen melalui pemberdayaan dalam proses pengambilan keputusan secara positif (Bogaert et al., 2016; Carrasco-Peralta et al., 2019). Selian itu, prediktor kualitas yang lebih baik selama dan setelah proses akreditasi karena kepemimpinan, komitmen dan dukungan, penggunaan data, manajemen kualitas, dan keterlibatan staf (El-Jardali et al., 2008). Dalam mempersipkan akreditasi klinik disarankan, pihak klinik harus membentuk tim khusus untuk mempersiapkan dan melengkapi semua dokumen pendukung yang dibutuhkan selama proses akreditasi (Anggraeny and Ernawaty, 2016; Nouwens et al., 2015). Tim akreditasi terdiri dari kepala eksekutif sebagai pelindungnya, tim inti bertanggung jawab kepada manajemen puncak melalui pelaporan rutin kepada komite pengatur dan manajemen, kebijaksanaan kolektif dari keanggotaan yang beragam tersebut membantu mengidentifikasi dan menganalisis masalah dari perspektif yang berbeda dan memastikan keputusan yang rasional, membuat perencanaan setelah konsultasi dan mempertimbangkan (Chiu et al., 2011). Penerapan tata kelola klinis yang efektif dalam praktik umum mungkin memerlukan reformasi budaya dan organisasi serta dukungan praktis. Mereka memusatkan perhatian mereka pada inisiatif pendukung dan melibatkan mereka dalam program untuk peningkatan kualitas perawatan (Campbell et al., 2002).

Komitmen pemilik klinik untuk meningkatkan kualitas layanan. Limato et al. (2019) menjelaskan pemimpinan yang mendukung, peningkatan mutu layanan dengan menjaga semangat individu, kolaborasi semua orang yang terlibat dalam organisasi, pendekatan kerja sama tim, budaya mutu organisasi dan akreditasi pelayanan kesehatan turut mendukung keberhasilan peningkatan mutu dalam pelayanan kesehatan. Komitmen pimpinan atau pemilik pelayanan kesehatan memiliki peran penting bagi kelangsungan proses akreditasi dengan menjaga hubungan dengan pegawai karena pegawai merupakan tokoh utama dalam upaya peningkatan mutu pelayanan sesuai standar akreditasi.

Pemimpin berperan dalam merangsang intelektual staf dengan mendorong ide-ide kreatif, meningkatkan perawatan standar berdasarkan prosedur layanan, dan membimbing staf; memberikan perhatian yang tulus, berkomunikasi dalam proses pengambilan keputusan; memberikan motivasi yang inspiratif, tercapainya target pencapaian di unit keperawatan, dan menumbuhkan semangat kerja sama tim; dan memberikan contoh dan pengaruh yang baik pada staf yang dipimpinnya (Ginting et al., 2017). Kodama et al. (2016) menjelaskan bahwa aspek stimulasi intelektual dari kepemimpinan transformasional secara positif meningkatkan komitmen staf perawat. Komitmen dan kepemilikan bersama antara pimpinan klinik, pemilik klinik, dan staf terhadap klinik berdampak positif dalam pencapaian tujuan klinik berkualitas dengan berbagai inovasi pelayanan. Selain itu, masyarakat dapat menjangkau pelayanan kesehatan secara sadar dan aman untuk memastikan kesehatannya meskipun belum memahami akreditasi. 
Simpulan

Dalam rangka menyukseskan akreditasi klinik, hasil pengabdian masyarakat ini menyoroti tiga faktor esensial yang dapat menghambat penyusunan akreditasi, yaitu faktor internal staf, faktor klinis, dan faktor komitmen pemilik dan staf klinik. Proses akreditasi diharapkan tidak hanya memenuhi kewajiban kepada pemerintah, tetapi menjadi budaya pelayanan kesehatan yang bermutu bagi komunitas dan memberikan manfaat bagi kesehatan pasien. Selain itu, perlu diperhatikan oleh institusi pendidikan untuk mengembangkan kompetensi tenaga kesehatan mengenai kualitas pelayanan atau akreditasi sejak pendidikan formal.

\section{Ucapan Terima Kasih}

Ucapan terima kasih kepada Pimpinan Pusat Muhammadiyah-Aisyiyah yang telah mendukung pengabdian masyarakat ini. Terima kasih kepada seluruh jajaran pimpinan, tim mutu Klinik Aisyiyah, dan Pimpinan Daerah Asiyiyah yang bersedia meningkatkan mutu pelayanan kesehatan dengan mengikuti pelatihan persiapan akreditasi klinik. Selain itu, ucapan terima kasih pengabdi tujukan kepada pemberi dana hibah pengabdian masyarakat yaitu LP3M UMY.

\section{Daftar Pustaka}

Agence Nationale d'Accréditation and d'Évaluation en Santé, 1999. Accreditation Manual For Health Care Organisations.

Alkhenizan, A., Shaw, C., (2012). The Attitude of Health Care Professionals Towards Accreditation: A Systematic Review of The Literature. J Family Community Med 19, 74-80. https://doi.org/10.4103/2230-8229.98281.

Alyahya, M., Hijazi, H., Harvey, H., (2018). Explaining the Accreditation Process from The Institutional Isomorphism Perspective: A Case Study of Jordanian Primary Healthcare Centers. Int J Health Plann Manage 33, 102-120. https://doi.org/10.1002/hpm.2397.

Anggraeny, P.A., Ernawaty, E. (2016). Kesiapan Pusat Layanan Kesehatan (PLK) B Unair Menghadapi Akreditasi Klinik Pratama. JAKI 4, 146. https://doi.org/10.20473/jaki.v4i2.2016.146-154.

Bogaert, P.V., Peremans, L., Diltour, N., Heusden, D.V., Dilles, T., Rompaey, B.V., Havens, D.S. (2016). Staff Nurses' Perceptions and Experiences about Structural Empowerment: A Qualitative Phenomenological Study. PLOS ONE 11, e0152654. https://doi.org/10.1371/journal.pone.0152654.

Campbell, S., Sheaff, R., Sibbald, B., Marshall, M., Pickard, S., Gask, L., Halliwell, S., Rogers, A., Roland, M. (2002). Implementing Clinical Governance in English Primary Care Groups/Trusts: Reconciling Quality Improvement and Quality Assurance. Qual Saf Health Care 11, 9-14. https://doi.org/10.1136/qhc.11.1.9.

Carrasco-Peralta, J.A., Herrera-Usagre, M., Reyes-Alcázar, V., Torres-Olivera, A. (2019). Healthcare Accreditation as Trigger of Organisational Change: The View of Professionals. J Healthc Qual Res 34, 59-65. https://doi.org/10.1016/j.jhqr.2018.09.007.

Chiu, A., Seto, W., Lai, L. (2011). Journey of A Hong Kong Public Teaching Hospital in Preparation of Hospital Accreditation. Hong Kong Med J 17, 231-6. 
Desveaux, L., Mitchell, J.I., Shaw, J., Ivers, N.M. (2017). Understanding the Impact of Accreditation on Quality in Healthcare: A Grounded Theory Approach. Int J Qual Health Care 29, 941-947. https://doi.org/10.1093/intqhc/mzx136.

Due, T., Thorsen, T., Kousgaard, M. (2019). Understanding Accreditation Standards in General Practice - A Qualitative Study. BMC Family Practice 20. https://doi.org/10.1186/s12875-019-0910-2.

El-Jardali, F., Jamal, D., Dimassi, H., Ammar, W., Tchaghchaghian, V. (2008). The Impact of Hospital Accreditation on Quality of Care: Perception of Lebanese Nurses. Int J Qual Health Care 20, 363-371. https://doi.org/10.1093/intqhc/mzn023.

Embrey, M., Vialle-Valentin, C., Dillip, A., Kihiyo, B., Mbwasi, R., Semali, I.A., Chalker, J.C., Liana, J., Lieber, R., Johnson, K., Rutta, E., Kimatta, S., Shekalaghe, E., Valimba, R., Ross-Degnan, D. (2016). Understanding the Role of Accredited Drug Dispensing Outlets in Tanzania's Health System. PLOS ONE 11, e0164332. https://doi.org/10.1371/journal.pone.0164332.

Francis, R., 2013. Report of the Mid Staffordshire NHS Foundation Trust Public Inquiry. London: TSO.

Ginting, B., Komariah, S., Bandur, A. (2017). Analisis Peran Kepemimpinan Transformasional dalam Mempertahankan Standar Care of Patient Sesuai Akreditasi JCI Di Rumah Sakit Awal Bros Tangerang. Ilmu Keperawatan dan Kebidanan 3.

Gollop, R., Whitby, E., Buchanan, D., Ketley, D. (2004). Influencing Sceptical Staff to Become Supporters of Service Improvement: A Qualitative Study of Doctors' and Managers' Views. Qual Saf Health Care 13, 108-114. https://doi.org/10.1136/qshc.2003.007450.

Greenfield, D., Pawsey, M., Hinchcliff, R., Moldovan, M., Braithwaite, J. (2012). The Standard of Healthcare Accreditation Standards: A Review of Empirical Research Underpinning Their Development and Impact. BMC Health Serv Res 12, 329. https://doi.org/10.1186/1472-6963-12-329.

Hinchcliff, R., Greenfield, D., Moldovan, M., Westbrook, J.I., Pawsey, M., Mumford, V., Braithwaite, J. (2012). Narrative Synthesis of Health Service Accreditation Literature. BMJ Qual Saf 21, 979-991. https://doi.org/10.1136/bmjqs-2012-000852.

Homolka, S., Zallet, J., Albert, H., Witt, A.-K., Kranzer, K. (2019). Introduction of Quality Management in A National Reference Laboratory in Germany. PLOS ONE 14, e0222925. https://doi.org/10.1371/journal.pone.0222925.

ISQua. (2015). Guidelines and Principles for The Development of Health and Social Care Standards 4th Edition Version 1.2. ISQua Accreditation, Ireland.

Jha, A.K. (2018). Accreditation, Quality, and Making Hospital Care Better. JAMA 320, 24102411. https://doi.org/10.1001/jama.2018.18810.

Jiang, T., Yu, P. (2015). The Relationship between Using Electronic Health Records and Meeting Accreditation Standards for Client Safety in Residential Aged Care Homes. Study Health Technol Inform 214, 134-138.

Kementerian Kesehatan RI (2015). PMK No. 46 tentang Akreditasi Puskesmas, Klinik Pratama, Tempat Praktik Mandiri Dokter dan Dokter Gigi.

Kementrian Kesehatan RI. (2019). Data dan Informasi Profil Kesehatan Indonesia 2018. Jakarta: Pusat Data dan Informasi Kemetrian Kesehatan.

Kodama, Y., Fukahori, H., Sato, K., Nishida, T. (2016). Is Nurse Managers' Leadership style Related to Japanese Staff Nurses' Affective Commitment to Their Hospital? J Nurs Manag 24, 884-892. https://doi.org/10.1111/jonm.12392.

Limato, R., Tumbelaka, P., Ahmed, R., Nasir, S., Syafruddin, D., Ormel, H., Kumar, M.B., Taegtmeyer, M., Kok, M. (2019). What Factors do Make Quality Improvement Work in Primary Health Care? Experiences of Maternal Health Quality Improvement Teams in 
Three Puskesmas in Indonesia. PLoS ONE 14, e0226804. https://doi.org/10.1371/journal.pone.0226804.

Mary, L., Myles, M., Suzanne, F.-L., David J, M. (2007). Hospital Response to Public Reporting of Quality Indicators. Health Care Financ Rev 28, 61-76.

Melo, S. (2016). The Impact of Accreditation on Healthcare Quality Improvement: A Qualitative Case Study. Journal of Health, Organisation and Management 30, 12421258. https://doi.org/10.1108/JHOM-01-2016-0021.

Mosadeghrad, A., Yousefinezhadi, T., Baba akbari, A. (2019). Evaluation of Hospital Accreditation Implementation in Iran 18, 23-35.

Mumford, V., Greenfield, D., Hogden, A., Forde, K., Westbrook, J., Braithwaite, J. (2015). Counting The Costs of Accreditation in Acute Care: an Activity-Based Costing Approach. BMJ Open 5. https://doi.org/10.1136/bmjopen-2015-008850.

Nicklin, W., Fortune, T., van Ostenberg, P., O’Connor, E., McCauley, N., (2017). Leveraging the Full Value and Impact of Accreditation. Int J Qual Health Care 29, 310-312. https://doi.org/10.1093/intqhe/mzx010.

Nouwens, E., van Lieshout, J., Wensing, M. (2015). Determinants of Impact of A Practice Accreditation Program in Primary Care: A Qualitative Study. BMC Fam Pract 16. https://doi.org/10.1186/s12875-015-0294-x.

Organización Panamericana de la Salud, Organización Mundial de la Salud, 140 a Sesón Del Comité Ejecutivo. (2007). Politica Y Estrategia Regionales Para La Garantia De La Calidad De La Atencion Sanitaria, Inclutendo La Seguridad Del Paciente.

Piontek, F.A., Coscia, R., Marselle, C.S., Korn, R.L., Zarling, E.J., American College of Surgeons. (2003). Impact of American College of Surgeons Verification on Trauma Outcomes. J Trauma 54, 1041-1046; discussion 1046-1047. https://doi.org/10.1097/01.TA.0000061107.55798.31.

Pomey, M.-P., François, P., Contandriopoulos, A.-P., Tosh, A., Bertrand, D. (2005). Paradoxes of French Accreditation. BMJ Quality \& Safety 14, 51-55. https://doi.org/10.1136/qshc.2004.011510.

Pongpirul, K., Sriratanaban, J., Asavaroengchai, S., Thammatach-Aree, J., Laoitthi, P. (2006). Comparison of Health Care Professionals' and Surveyors' Opinions on Problems and Obstacles in Implementing Quality Management System in Thailand: A National Survey. Int J Qual Health Care 18, 346-351. https://doi.org/10.1093/intqhe/mzl031.

Restiawati, E.K., Rudijanto, A., Wardhani, V. (2013). Respon Pemimpin Rumah Sakit terhadap Penerapan Akreditasi Rumah Sakit KARS Versi 2012. Jurnal Manajemen Palayanan Kesehatan 16, 9-14.

Saadati, M., Yarifard, K., Azami-Agdash, S., Tabrizi, J.S. (2015). Challenges and Potential Drivers of Accreditation in the Iranian Hospitals. International Journal of Hospital Research 4, 37-42.

Salmon, J.W., Heavens, J., Lombard, C., Tavrow, P. (2003). The Impact of Accreditation on the Quality of Hospital Care: KwaZulu-Natal Province, Republic of South Africa. Bethesda, MD: the U.S. Agency for International Development (USAID) by the Quality Assurance Project, University Research Co., LLC.

Sharma, J., Leslie, H.H., Kundu, F., Kruk, M.E. (2017). Poor Quality for Poor Women? Inequities in the Quality of Antenatal and Delivery Care in Kenya. PLoS One 12. https://doi.org/10.1371/journal.pone.0171236.

Tabandeh, S., Najmeh, G., Hadi, K., Hamid, S.B.S., Mehdi, K., Esmat, N., Sakine, S. (2016). Assessment Managers' and Hospital Staff Knowledge and Attitude to Accreditation 5, 9-17.

Tabrizi, J.S., Azami-Aghdash, S., Abdollahi, L., Daemi, A., Fard, K.Y., Valizadeh, S., Abhari, A.A., Saadati, M., Kabiri, N., Nadimi, B. (2019). Required Infrastructures to Implement 
Accreditation in Iran: The Perspective of Top Managers of the Teaching Hospitals in Tabriz and Ardabil University of Medical Sciences. Depiction of Health 4, 29-34.

WHO. (2006). Electronic Health Records Manual for Developing Countries. World Health Organization, Geneva.

WHO. (2003). Quality and Accreditation in Health Care Services A Global Review. World Health Organization Geneva.

Yu, P., Jiang, T., Hailey, D., Ma, J., Qian, S. (2020). The Contribution of Electronic Health Records to Risk management Through Accreditation of Residential Aged Care Homes in Australia. BMC Med Inform Decis Mak 20. https://doi.org/10.1186/s12911-020-1070-y.

Yu, P., Wang, N., Hailey, D.M., Oxlade, D.M.D. (2009). Developing Approaches to Measure the Quality of Electronic Versus Paper-Based Nursing Documentation in Aged Care Homes. University of Wollongong Australia.

Zarifraftar, M., Aryankhesal, A. (2016). Challenges of Implementation of Accreditation Standards for Health Care Systems and Organizations: A Systematic Review. 